\title{
Mapping the balance between grain supply and demand globally - GIS-based transport accessibility
}

\author{
Kotavaara, O. ${ }^{\text {a }}{ }^{*}$, Ala-Hulkko, T. a \& b , Toivanen, M. ${ }^{\text {a } \& b}$, Poturalska, A. ${ }^{\text {a } \& ~ b}$, Magyar, M. ${ }^{\text {a }}$, \\ Kinnunen, P. ${ }^{c}$ \\ ${ }^{a}$ University of Oulu, Kerttu Saalasti Institute, Oulu, Finland, ossi.kotavaara@oulu.fi, marton.magyar@oulu.fi \\ ${ }^{b}$ University of Oulu, Geography research unit, Oulu, Finland, terhi.ala-hulkko@oulu.fi,maija.toivanen@oulu.fi, \\ anita.poturalska@oulu.fi \\ ${ }^{c}$ Aalto university, Department of Built Environment, Espoo, Finland, pekka.kinnunen@aalto.fi \\ * Corresponding author
}

Keywords: Accessibility, Demand, Food, GIS, Global, Maritime, Network, Road, Supply

\begin{abstract}
:
Hunger is one of the biggest global problems for humankind that has not been solved by the 21 st century. Despite the satisfactory level of global food production, shortage of food is still a problem in some of the less-developed countries. Problems in food safety are the biggest in Africa, Asia, Latin America and the Near East. There are 795 million people who do not get enough calories and nutrients from food globally. President of American Association of Geographers Glen M. MacDonald (2016) named the question of food and famines as one of the key research agendas in geography. Depending on the future development trends, food problem may even get worse in the future due to steep population growth in the developing countries and negative effects of climate change on food production. One of the main reasons for the unequal distribution of hunger is socio-economic factors. In the future, climate change, population growth, increasing socio-economic differences, natural disasters and political conflicts are likely to increase the problem. To ease the food shortage (e.g. by developing agricultural policies, farming practices and food markets), we need timely and accurate information on global food accessibility.

Regional balance between production and consumption, as well as differences in transport system conditions among regions, have a key role in satisfying demand. Aim of this study is to explore spatial mismatch between proxies of food grain production and consumption in accurately localised data. This study can plausible be executed thanks to rapid development in open-source geospatial data and its applicability in Geographic Information Systems (GIS)-based analyses. Analysis of the study include the distribution of population, food resources and accessibility by road and maritime transports at the same time. Data of the study consists of food grain supply and demand (Kinnunen et al. 2020) and multimodal global transport network model consisting of road network by NASA gROADS 2010, major ports by World Port Index 2019 and maritime connections by CIA Map of the World Oceans 2012 enhanced by raster (Figure 1).
\end{abstract}

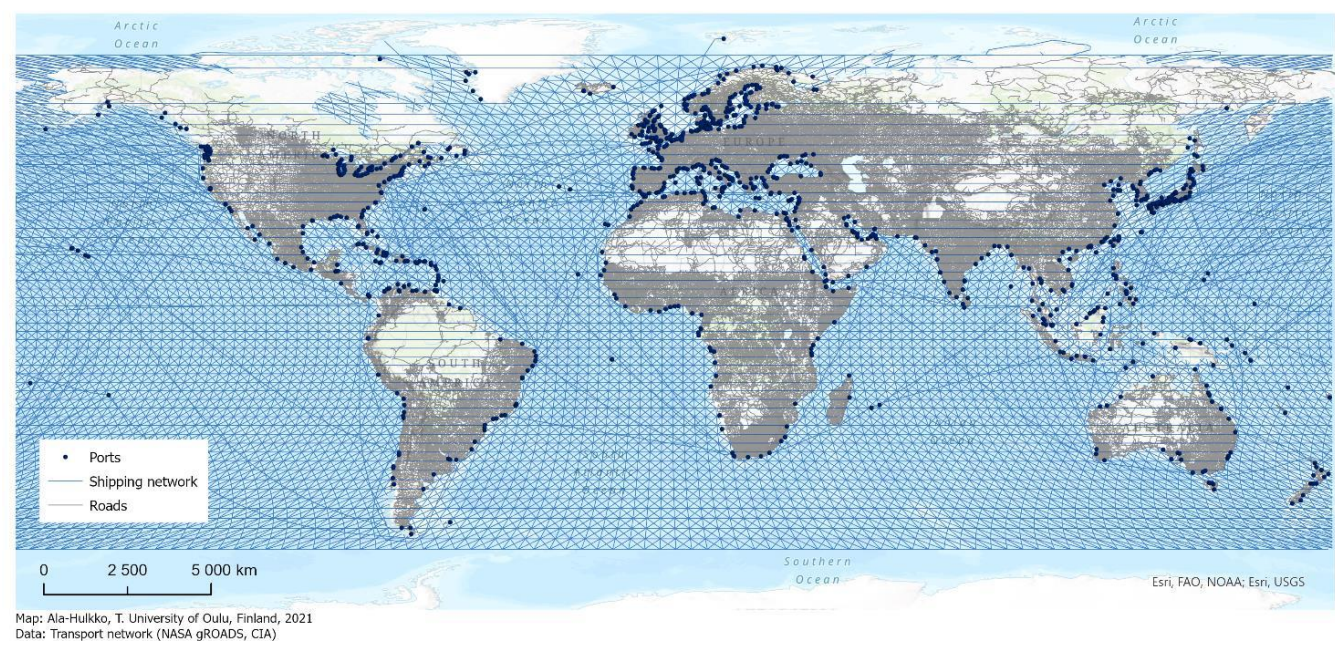

Figure 1. Global transport network model consisting of road network, major ports and maritime routing. 
Accessibility is measured by Enhanced Two-Step Floating Catchment Area (E2SFCA) -method, which is developed in the field of health geography (Luo \& Wang 2003), but is appicalble to measure spatial (mis)match of supply and demand of food (Ala-Hulkko et al. 2019). The method is a special case of a gravity model and is easy to use, interpret and understand as it measures accessibility in two steps by considering both supply and demand. Its importance lies in the improvement where it combines supply, demand and transport network information into a single spatial index that allows comparisons to be made across different locations. The 2SFCA technique was enhanced further to include a distance decay parameter within catchments (Luo \& Qi 2009). As a result, this analysis assigns accessibility scores determined by the supply to demand ratio.

\section{The balance between supply and demand of grains using regional transportation threshold}

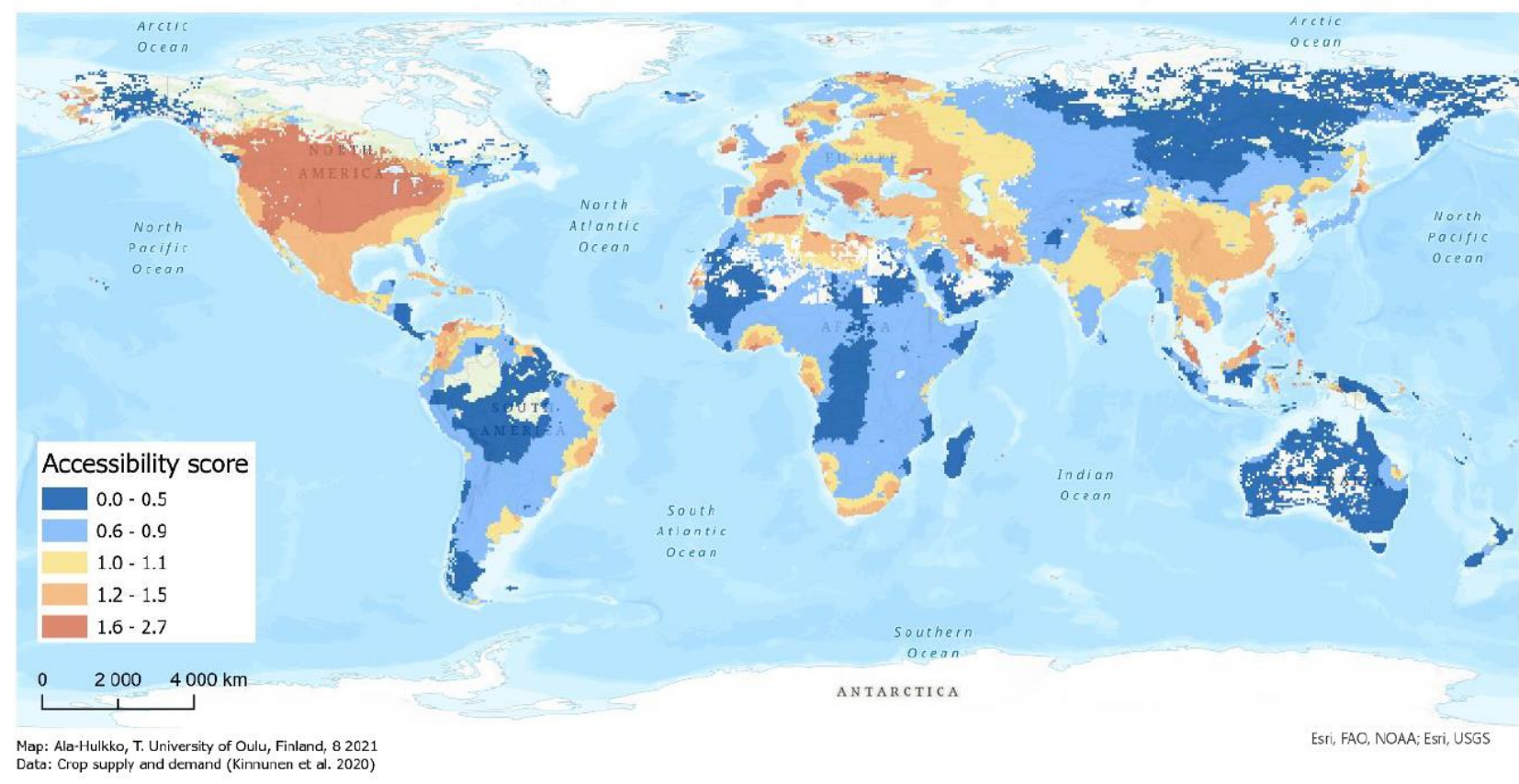

Figure 2. The balance between supply and demand of grains across the world using a regional transportation threshold. Values less than one (blues) indicates less supply than demand. Values close to one (yellow) indicates a balance between crop supply and demand, while values greater than one (reds) represent surplus areas.

Preliminary result indicates that global accessibility of grains (Figure 2.) varies significantly when regional supply and demand as well as transport accessibility are considered together. High accessibility score refers to high regional supply in relation to regional demand. Highest scores can be found from North America, coast of South America, Western and Eastern Europe, Mediterranean area, Southern Africa, southern Far East and Asia. Whereas, Siberia, Arabian Peninsula, Australia as well as central Africa and central South America seem to be most vulnerable regions in sigh of regional food accessibility. Reported results are, however, research in progress and analyses are evaluated, enhanced, and updated before final publishing.

\section{References}

Ala-Hulkko, T., O. Kotavaara, J. Alahuhta and J. Hjort (2019). Mapping supply and demand of a provisioning ecosystem service across Europe. Ecological Indicators 103: 520-529

MacDonald G. M. (2016) Geographies of Bread and Water in the 21st Century. AAG newsletter. DOI: $10.14433 / 2016.0012$

Luo, W. \& Qi, Y. (2009). An enhanced two-step floating catchment area (E2SFCA) method for measuring spatial accessibility to primary care physicians. Healt \& Place, 15, 1100-1107. https://doi.org/doi:10.1016/j.healthplace.2009.06.002

Luo, W. \& Wang, F. (2003). Measures of spatial accessibility to health care in a GIS environment: synthesis and a case study in the Chicago region. Environment and Planning B: Planning and Design, 30, 865-884. https://doi.org/10.1068/b29120

Kinnunen, P., Guillaume, J. H., Taka, M., D’Odorico, P., Siebert, S., Puma, M. J., Jalava, M. \& Kummu, M. (2020). Local food crop production can fulfil demand for less than one-third of the population. Nature Food, 1(4), $229-237$. 